\section{Composition of the Grignard Reagent}

IN 1912 Jolibois $^{1}$ suggested that the formula of the Grignard reagent was $R_{2} \mathrm{Mg} \cdot \mathrm{Mg} X_{2}$, and since that time there have been several controversial papers dealing with experimental evidence for and against this idea. The work of W. Schlenk and W. Schlenk, jun. ${ }^{2,8}$, in which the halogen was entirely precipitated from ether solutions of the Grignard reagent with dioxane, leaving dialkylmagnesium, led them to favour a slow equilibrium in the reaction

$$
2 R \mathrm{Mg} X \rightleftharpoons R_{2} \mathrm{Mg}+\mathrm{Mg} X_{2}
$$

as the best explanation of the results obtained. This idea of the composition of the Grignard reagent has been popularly held ever since, in spite of many reasons for doubting how anything so simple can fit all the complex results obtained-for example, those of Noller and Whites, in which dialkylmagnesium returned to the solution on further shaking the precipitate with the solution after precipitation.

The results of Noller and White are perfectly understandable on the basis of the slow equilibrium of $R \mathrm{MgX}$ and a complex of $R_{2} \mathrm{Mg}$ with $\mathrm{MgX}_{2}$ never being obtained,

$$
2 R \mathrm{Mg} X \rightleftharpoons\left[R_{2} \mathrm{Mg} \cdot \mathrm{MgX} X_{2}\right],
$$

and the postulate that there is practically no free dialkylmagnesium in the ordinary Grignard solution. (Incidentally, the ease with which dialkylmagnesium solutions catch fire as compared with those of the Grignard reagent is difficult to account for on any other basis.) Any solution containing $R_{2} \mathrm{Mg} \cdot \mathrm{Mg} \bar{X}_{2}$ will be in equilibrium with a small but finite amount of $R_{2} \mathrm{Mg}$ according to the equation

$$
R_{2} \mathrm{Mg} \cdot \mathrm{MgX} X_{2} \rightleftharpoons R_{2} \mathrm{Mg}+\mathrm{MgX},
$$

requiring that

$$
\frac{\left(R_{2} \mathrm{Mg}\right)\left(\mathrm{Mg} X_{2}\right)}{\left(R_{2} \mathrm{Mg} \cdot \mathrm{Mg} X_{8}\right)}=K_{1}
$$

As soon as a solution becomes saturated with respect to $R_{2} \mathrm{Mg} \cdot \mathrm{Mg} X_{2}$, the concentration of this complex is constant and

$$
\left(R_{2} \mathrm{Mg}\right)\left(\mathrm{Mg} X_{2}\right)=K_{2} .
$$

When dioxane is added to the solution, both com. pounds in equation $(B)$ are precipitated, and only after sufficient dioxane has been added to make the solution saturated with respect to $\mathrm{Mg} X_{2}$ (present in only small concentrations) can the $R_{2} \mathrm{Mg}$, originally present as $R_{2} \mathrm{Mg} \cdot \mathrm{Mg} X_{2}$, return to the solution, as will then be required to satisfy equation (1). In fact, equation (2) requires a fixed concentration of $R_{2} \mathrm{Mg}$ for a given ratio of dioxane to ether when $\mathrm{Mg} \bar{X}_{2}$ starts to be precipitated. The $R \mathrm{MgX}$, of course, stays in the precipitate.

We have been able to demonstrate that a solution of methylmagnesium iodide in di- $n$-butyl ether contains no free dimethylmagnesium by some extremely simple and conclusive experiments.

Brugger $^{5}$ found that such solutions reacted with acetone in di- $n$-butyl ether very rapidly (half-life about $7 \times 10^{-3}$ sec. at $27^{\circ}$ ) according to a reaction independent of the acetone concentration and dependent on the first power of the total Grignard concentration. Exactly the same rate $\left(k_{1} \approx 100 \mathrm{sec}^{-1}\right.$ at $27^{\circ}$ ) was obtained with ethyl acetate.

Recently, we have carried out similar experiments with solutions of dimethylmagnesium prepared by precipitation from diethyl ether with dioxane, and transferred to di- $n$-butyl ether by distilling the dioxane and ethyl ether away, using a good fractionating column, under an atmosphere of nitrogen after adding di- $n$-butyl ether. The rate was found at $27^{\circ}$ to be about fifty times that observed by Brugger. In this experiment, the final constant temperature down the tube of the rapid-rate apparatus ${ }^{6}$ corresponded approximately with the total heat $(48.4$ k.cal.) determined in our laboratory ${ }^{7,8}$ on the basis that only one methyl group reacted per mole of dimethylmagnesium; whereas, in Brugger's experiments, it varied from 25 to 40 per cent of the rise expected from the heat determined in this laboratory calculated on the basis of all being $\mathrm{CH}_{3} \mathrm{MgI}$, but 50-80 per cent on the basis of all being $\left(\mathrm{CH}_{3}\right)_{2} \mathrm{Mg}$, with only one methyl group reacting.

Quite clearly there can be no appreciable amount of free dimethylmagnesium in the di- $n$-butyl ether solution of the Grignard reagent, and the slower rate of reaction in this case is either due to the rate of dissociation of $\left(\mathrm{CH}_{3}\right)_{2} \mathrm{Mg}$.MgI $\mathrm{Mg}_{2}$, or, less likely, the slow rate of dissociation of $\mathrm{CH}_{3} \mathrm{MgI}\left[\left(\mathrm{C}_{4} \mathrm{H}_{9}\right)_{2 x} \mathrm{O}\right]$.

This last conclusion is made necessary because the total heat liberated when methyl magnesium iodide reacted with acetone in the rapid-rate apparatus, at the point down the tube where the temperature became constant, is only a fraction of the measured heat of the reaction. This fact indicates that one of these species must react very slowly. Assuming that the rate of the $\left(\mathrm{CH}_{3}\right)_{2} \mathrm{Mg} . \mathrm{MgI}_{2}$ dissociation determines the rate, Brugger's results point to more than 50 per cent of the Grignard solution existing as $\left(\mathrm{CH}_{3}\right)_{2} \mathrm{Mg} \cdot \mathrm{MgI}_{2}$, or the other assumption to more than 60 per cent. Further experiments are in progress.

The conclusion that the Grignard reagent has the formula

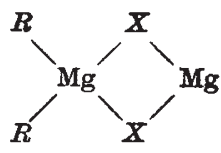

has been made previously by Evans and Lee from experiments on electrolysis and transference.

\section{J. G. Aston}

S. A. Bernhard

Department of Chemistry,

School of Chemistry and Physics,

Pennsylvania State College, $\mathrm{Pa}$. Nov. 7.

'Jolibois, C.R. Acad. Sci., Paris, 155, 353 (1912).

Schlenk, W., and Schlenk, W., jun., Ber., 62, 920 (1929).

${ }^{3}$ Schlenk, W., jun., Ber., 64B, 734 (1931).

' Noller, C. R., and White, W. R., J. Amer. Chem. Soc., 59, 1354 (1937).

- Brugger. J. E., M.S. Thesis, Penn. State College (1946).

This apparatus was essentially like that of La Mer and Reed ( $J$. Amer. Chem. Soc., 52,$3098 ; 1930$ ), with the fraction which had reacted down the tube measured by the temperature-rise indicated by suitably placed thermocouples.

- Aston, J. G., andझBernhard, S. A. (to be published).

${ }^{8}$ Aston, J. G., and? Kennedy, R. M. (to be published).

- Evans, W. v., and Lee, F. H., J. Amer. Chem. Soc., 56, 654 (1934).

\section{Polarographic Behaviour of Acetone}

IN supporting electrolytes generally used in polarography, for example, in solutions of potassium, lithium or ammonium salts or lithium hydroxide or in buffer solutions, no polarographic reduction wave of acetone can be observed. Only if electrolytes of tetra-alkylammonium are used can a reduction wave at a half-wave potential of about $-2 \cdot 1 \mathrm{~V}$. (from 